\title{
Normalizing the Arm Reaching Patterns after Stroke through Forced Use Therapy - A Systematic Review
}

\author{
Senthilkumar Jeyaraman ${ }^{1}$, Ganesan Kathiresan ${ }^{2}$, Kavitha Gopalsamy ${ }^{3}$ \\ ${ }^{1}$ Physiotherapy, School of Therapeutic Sciences, Masterskill University College of Health sciences, Cheras, Malaysia; ${ }^{2}$ Physiother- \\ apy, School of Allied Health, Masterskill University College of Health sciences, Sabah, Malaysia; ${ }^{3}$ Physiotherapist, Cheras, Malay- \\ sia. \\ Email: senmpt@yahoo.com, \{gans_therapist, gopalsamykavitha\}@yahoo.co.in
}

Received June $10^{\text {th }}$, 2010; revised June 25 ${ }^{\text {th }}, 2010$; accepted June 30 ${ }^{\text {th }}, 2010$.

\begin{abstract}
Hemiparesis is common following stroke. The ability to reach and grasp is a necessary component of many daily life functional tasks, hence reduced upper limb function has an impact on the ability to perform activities of daily living. In hemiparetic patients, the unrestricted and unguided repetition of a motor task may reinforce compensatory movements. Trunk restraint allowed the patients to use joint ranges that were present but not recruited during unrestrained reaching. Later, studies combined the trunk restraint training with additional therapeutic interventions. With the growing number of studies on this intervention in the stroke population, there is the need to consolidate this evidence to determine the potential use of trunk restraint training in improving arm reaching in neurological rehabilitation particularly for stroke patients. A considerable research effort had assessed the effects of trunk restraint training on the recovery of reaching movements in hemiparetic patients. This review identified 5 relevant trials in which one trial is a pilot study. Among 5 trials, three trials recorded the movement kinematics (outcome measure) by Optotrak Motion analysis System, in the other two trials the movement kinematics (outcome measure) were analysed by a 6 - camera, 3D Motion analysis system and 10 - camera Motion Analysis System respectively. The effect size for the intervention was calculated by Cohen's $d$. In this review, for the meta-analysis we used trunk displacement, trunk flexion, elbow extension, Smoothness and hand trajectory straightness (movement variables in kinematic analysis). The results of our review demonstrated that the use of trunk restraint as a treatment paradigm aimed at decreasing compensatory strategies has the potential of becoming an effective therapy. Further studies are necessary to determine the long term effect of the trunk restraint training.
\end{abstract}

Keywords: Stroke, Trunk Restraint, Reaching

\section{Introduction}

Research on the effectiveness of rehabilitation techniques for patients with stroke is important not only for stroke survivors but also for care givers, treatment providers and society alike. The ability to reach and grasp is a necessary component of many daily life functional tasks, hence reduced upper limb function has an impact on the ability to perform activities of daily living [1], which is likely to reduce independence and increase burden of care. In the months after stroke, function of the paretic arm can improve as reaching; grasping and manipulating ability is regained. Improvements in function can occur in 2 ways. In one way, premorbid movement patterns may be regained because of true motor recovery. In another way, because of the redundancy in the number of degrees of freedom (DFs) of the body [2], actions can be accompanied by substitution of other DFs for movements of impaired joints. These alternative movements or motor compensations [3] are also observed in animals recovering from experimental stroke [4,5].

In patients with hemiparesis, the unrestricted and unguided repetition of a motor task may reinforce compensatory movements. Reference [6] patients with severe impairment tend to improve performance (defined as movement speed, precision and smoothness) of a pointing 
movement after 1 day of intensive training by incorporating trunk anterior displacement, a movement not normally needed for the task. Thus, in the short term, although compensatory movements may improve performance of the paretic arm, in the long term, these may be maladaptive by preventing recovery or reappearance of more efficient arm movement patterns [7].

Although neurorehabilitation research has recently demonstrated that structured, specific, and intensive training protocols increase the amount of hemiparetic limb use, less attention has been given to normalizing movement strategies poststroke [8]. Hence, Michaelsen et al. evaluated movement patterns of the hemiparetic arm made with or without restriction of compensatory trunk movements during reach to grasp tasks and found restriction of compensatory trunk movements may encourage recovery of 'normal' reaching patterns in the hemiparetic arm when reaching for objects placed within arm's length. During trunk restraint, patients improved active elbow extension, shoulder ranges and interjoint coordination when reaching [9-11]. Trunk restraint thus allowed patients to use joint ranges that were present but not recruited during unrestrained reaching. Later, studies combined the trunk restraint training with additional therapeutic interventions [12,13].

With the growing number of studies on this intervention in stroke population, there is a need to consolidate this evidence to determine the potential use of trunk restraint training in improving arm reaching in neurological rehabilitation particularly for stroke patients.

\section{The Review}

\subsection{Aim}

1) The primary aim is, to assess the effectiveness of trunk restraint training on the recovery of reaching movements in stroke patients.

2) Secondary aim is, to find out the effectiveness of trunk restraint training combined with other therapeutic interventions.

\subsection{Inclusion Criteria}

\subsubsection{Type of Studies}

To determine the evidence of the effectiveness of trunk restraint practice in neurological rehabilitation of stroke patients, randomised controlled clinical trials (RCTs) was the study design of choice. Clinical controlled trials (CCTs), quasi experimental studies, descriptive studies were also considered in the absence of RCTs.

\subsubsection{Types of Participants}

This review included any study involving any adult person with stroke, except those with pathology of the cerebellum or the basal ganglia (Table 1).

\subsubsection{Types of Interventions}

Trunk restraint training, Trunk restraint training combined with other interventions (Table 2).

\subsection{Outcome Measures}

\subsubsection{Clinical}

- Fugl-Meyer Assessment (arm section).

- TEMPA Scale.

- Manual Dexterity (Box and Block Test).

- Isometric Force (Handheld \& handgrip Dynamometers).

- AROM (Active Range of Motion).

- Composite Spasticity Index.

- Wolf Motor Function Test.

- Motor Activity Log-Amount of Use Scale and Quality of Movement Scale.

\subsubsection{Kinematic}

- Motion analysis system.

\subsection{Search Strategy for Identification of Studies}

\subsubsection{Language}

Published English language studies were sought.

\subsubsection{Keywords}

Chronic stroke, arm, reaching, trunk restraint training.

Studies identified during the database searches from 2000 to 2009 were assessed for relevance from a review of the title, abstract and descriptors of the study. The databases that were searched included:

- CINAHL,EMBASE, MEDLINE, Cochrane library, PEDro, Pubmed, Ovid (Figure 1).

\subsection{Data Extraction}

Study outcome data were collected by one reviewer and

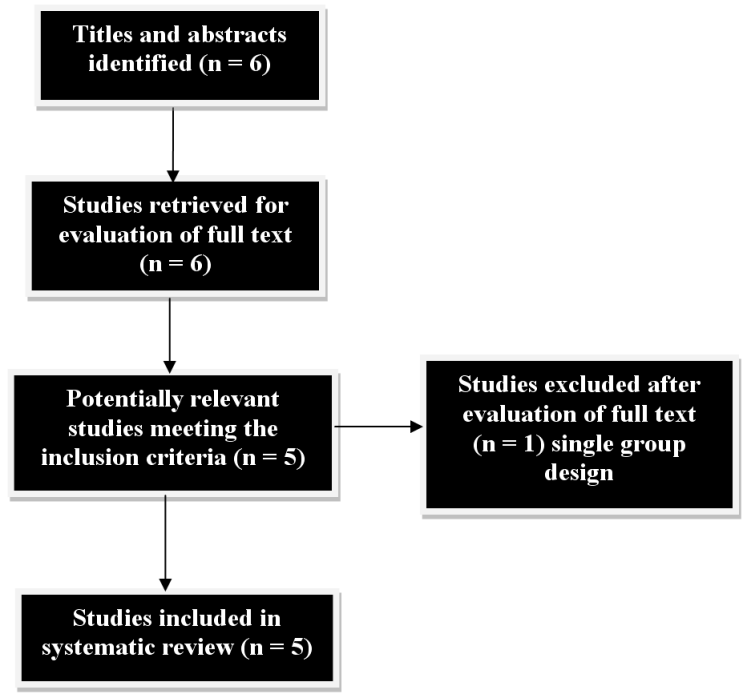

Figure 1. Search outcome. 
Table 1. Criteria for inclusion of participants in studies.

\begin{tabular}{|c|c|c|c|c|c|}
\hline Criteria & $\begin{array}{l}\text { SM Michaelsen } \\
\text { et al. } 2001\end{array}$ & $\begin{array}{l}\text { SM Michaelsen } \\
\text { et al. } 2004\end{array}$ & $\begin{array}{l}\text { SM Michaelsen } \\
\quad \text { et al. } 2006\end{array}$ & $\begin{array}{l}\text { G Thielman et al. } \\
2008\end{array}$ & $\begin{array}{l}\text { ML Woodbury } \\
\text { et al. } 2009\end{array}$ \\
\hline $\begin{array}{c}\text { Time since onset of } \\
\text { stroke }\end{array}$ & 5 to 69 months & 7 to 94 months & 6 to 48 months & 7 to 36 months & 6 to 101 months \\
\hline Age (Years) & $>20$ & $<80$ & $<85$ & $<90$ & 18 to 90 \\
\hline Specified diagnosis & $\mathrm{X}$ & - & - & $\mathrm{X}$ & - \\
\hline $\begin{array}{l}\text { Specified side of } \\
\text { Hemiplegia }\end{array}$ & $\mathrm{X}$ & $\mathrm{X}$ & $\mathrm{X}$ & $\mathrm{X}$ & $\mathrm{X}$ \\
\hline $\begin{array}{l}\text { No evidence of excessive } \\
\text { Spasticity }\end{array}$ & $\mathrm{X}$ & $\mathrm{X}$ & - & - & - \\
\hline No excessive pain & $\mathrm{X}$ & $\mathrm{X}$ & $\mathrm{X}$ & - & $\mathrm{X}$ \\
\hline $\begin{array}{l}\text { Measurement of reduced } \\
\text { upper limb function }\end{array}$ & $\mathrm{X}$ & $\mathrm{X}$ & $\mathrm{X}$ & $\mathrm{X}$ & $\mathrm{X}$ \\
\hline Specified level of Balance & $\mathrm{X}$ & - & - & - & - \\
\hline $\begin{array}{l}\text { Not participating in an } \\
\text { active rehabilitation } \\
\text { program }\end{array}$ & - & $\mathrm{X}$ & - & $\mathrm{X}$ & - \\
\hline $\begin{array}{c}\text { Not part of other } \\
\text { experimental studies }\end{array}$ & - & - & - & $\mathrm{X}$ & - \\
\hline $\begin{array}{l}\text { No upper limb conditions } \\
\text { limiting use before stroke }\end{array}$ & $\mathrm{X}$ & $\mathrm{X}$ & $\mathrm{X}$ & $\mathrm{X}$ & $\mathrm{X}$ \\
\hline $\begin{array}{l}\text { No other significant } \\
\text { medical conditions }\end{array}$ & $\mathrm{X}$ & $\mathrm{X}$ & $\mathrm{X}$ & $\mathrm{X}$ & $\mathrm{X}$ \\
\hline $\begin{array}{l}\text { Specification of hand } \\
\text { dominance }\end{array}$ & - & $\mathrm{X}$ & - & - & $\mathrm{X}$ \\
\hline $\begin{array}{l}\text { No evidence of severe } \\
\text { perceptuocognitive } \\
\text { deficits }\end{array}$ & $\mathrm{X}$ & $\mathrm{X}$ & $\mathrm{X}$ & $\mathrm{X}$ & $\mathrm{X}$ \\
\hline $\begin{array}{l}\text { Able to perform reach to } \\
\text { grasp movement }\end{array}$ & - & $\mathrm{X}$ & $\mathrm{X}$ & $\mathrm{X}$ & $\mathrm{X}$ \\
\hline $\begin{array}{l}\text { No limitations in passive } \\
\text { range of motion }\end{array}$ & - & $\mathrm{X}$ & - & - & $\mathrm{X}$ \\
\hline
\end{tabular}

Table 2. Description of trunk restraint procedures.

Author

SM Michaelsen et al. (2001)

SM Michaelsen et al. (2004)

SM Michaelsen et al. (2006)

G Thielman et al. (2008)

ML Woodbury et al. (2009)

\section{Restraint Procedures}

Trunk was secured to the chair back with the harness minimizing shoulder girdle movement and preventing trunk flexion and rotation

Participants wore a harness consisting of breast and back plates connected by adjustable straps. An electromagnet attached to the wall was locked to the back electromagnetic plate at the interscapular level

Trunk movements were prevented by body and shoulder belts attached to the chair back. Scapular elevation / protraction were not restricted.

Restraining device (LL Bean Co, Freeport, ME) was attached to the chair's back and had 2 padded shoulder straps that come across the glenohumeral joint, permitting approximately $3 \mathrm{~cm}$ of scapula motion but limiting trunk flexion.

To discourage anterior trunk displacement a custom designed trunk restraint was placed between the participant and the table. The restraint was placed between the participant and the table. The restraint was constructed on a stable base designed to fit around the outside of a chair while allowing the chair to slide under it to the table. The restraint was adjusted in height so that a padded shield was located anterior to and lightly touching the participant's sternum. 
checked by a second reviewer. The following study characteristics were recorded on a data extraction form: setting and phase, study design and population, intervention, outcome and measurement.

\subsection{Data Analysis}

The effect size for the intervention was calculated by Cohen's d [14,33]. The effect sizes are especially important because they allow us to compare the magnitude of experimental treatments from one experiment to another. Estimates from individual studies are combined to reflect the overall size of the effect of the independent variable. The larger the difference, the greater the 'effect' of the intervention. If the effect size is $>=-0.15$ and $<0.15$, the effect is negligible, if the effect size $>=0.40$ and $<0.75$, it is said to be medium effect, while the effect size is $>$ 1.45, the effect is said to be huge. The size of percentage change is also calculated.

In this review, for the meta-analysis we used the following movement variables in kinematic analysis (outcome measure),

* trunk displacement,

trunk flexion,

* elbow extension,

* Smoothness and hand trajectory straightness.

\subsection{Results}

The search yielded 6 full text articles, following the exclusion based on the criteria; 5 articles were included. Among the 5 articles included, one was done in Canada with 11 healthy and 11 hemiparetic individuals [9], the another two studies were studied in Canada with 28 hemiparetic patients and 30 patients respectively [10,11]. The fourth one was done in New York with 11 patients [12]; fifth study was done with 12 strokes, 5 health individuals in Florida [13].

Michaelson SM et al. [9-11] studied the effect of trunk restraint training on the recovery of reaching movements in chronic hemiparetic patients. Thielman G. et al. [12] studied the task related training and resisted exercise combined with trunk restraint training. Woodbury ML et al. [13] combined the trunk restraint training with intensive task practice and studied its effects on reach and function.

Participants across all the trails had similar diagnosis of hemiparesis with more upper limb involvement. All the trails exclude the patients with hemispatial neglect or apraxia, shoulder pain or neurologic or orthopaedic conditions affecting the arm or trunk.

The duration of the trail, setting type, intensity and type of therapy varied across trails which are described in
Table 3. The effect sizes and percentage change for the outcome measure was calculated for both treatment and control groups. It was described in the Tables 4, 5, 6, 7, $\mathbf{8}$, which revealed negligible effect to very large effect sizes and negligible change to large decrease respectively.

\subsubsection{Trunk Restraint Training and Recovery of Reaching}

Three of the five trials studied the effect of trunk restraint training on reaching movements in patients with chronic stroke. All the three trials were done by SM. Michaelson et al. [9-11]. In the first trial, he included 11 healthy and 11 hemiparetic individuals. Data was collected with the use of an Optotrak Motion Analysis System. He concluded that trunk restraint decreases the number of joints involved in reaching. The effect sizes for elbow extension is 1.24 (Very large effect) in trunk restraint training. The percentage changes from comparison to treatment groups for elbow extension are -15 (Medium decrease). In this study, elbow extension was increased on an average of 14 degrees.

In the second study, 28 hemiparetic were assigned into two groups. The outcome measure was Optotrak motion Analysis system. The author concluded that restriction of compensatory trunk movements during practice may lead to greater improvements in reach - to - grasp movements in patients with chronic stroke than practice alone. The effect sizes for trunk displacement is 0.58 (Medium effect) and elbow extension is 0.29 (small effect). The percentage changes from comparison to treatment group for trunk displacement is -33 (Large decrease) and elbow extension is 7 (Small increase). Individual analysis of hemiparetic patients in trunk restraint group showed an increase in elbow extension ( $>10$ degrees) between pre-test and retention test; Anterior trunk displacement was decreased significantly more (by $52 \mathrm{~mm}$ ) in trunk restraint patients.

In the third trial, Michaelsen randomly assigned 30 patients into trunk restraint group and control group. The author concluded that treatment should be tailored to arm impairment severity with particular attention to controlling excessive trunk movements if the goal is to improve arm movement quality and function. The effect sizes for smoothness (in whole group) is 0.22 (Small effect) and hand trajectory straightness (in whole group) is 0 (negligible effect). The percentage changes from comparison to treatment group for smoothness is -10 (Small decrease) and hand trajectory straightness is 0 (negligible change). Kinematic analysis revealed that trunk restraint decreased mean trunk displacement by $32.8 \mathrm{~mm}$ at post-test; at the same time trunk restraint increased elbow extension by 5.9 degrees at post-test. 
Table 3. Summary of trial design features.

\begin{tabular}{|c|c|c|c|c|}
\hline $\begin{array}{c}\text { Study } \\
\text { (First author) }\end{array}$ & Setting & $\begin{array}{c}\text { Intensity of } \\
\text { therapy }\end{array}$ & Type of therapy & Additional therapy \\
\hline Michaelsen 2001 & Inpatient & 20 trials & $\begin{array}{l}\text { With trunk restraint and with full vision, partici- } \\
\text { pants reached toward, grasped and returned the } \\
\text { cone to the midchest region at a comfortable self } \\
\text { paced speed. Reaches to target } 1 \text { and target } 2 \\
\text { repeated with trunk secured to the chair back with } \\
\text { a harness. }\end{array}$ & Nil \\
\hline Michaelsen 2004 & Inpatient & $\begin{array}{l}60 \text { trial training } \\
\text { period on day } 1 \text { and } \\
\text { in a single session } \\
\text { on day } 2\end{array}$ & $\begin{array}{l}\text { Participants reached and grasped a cylinder in } \\
\text { response to an auditory signal. Both groups were } \\
\text { instructed not to move the trunk and to use as } \\
\text { much as elbow extension }\end{array}$ & Nil \\
\hline Michaelsen 2006 & Inpatient & $\begin{array}{l}1 \text { hour therapist } \\
\text { supervised program } \\
3 \text { times per week for } \\
5 \text { weeks(total }=15 \\
\text { sessions) }\end{array}$ & $\begin{array}{l}\text { With trunk restraint, repetitive functional uni- and } \\
\text { bimanual reach to grasp tasks using objects vary- } \\
\text { ing in size, weight and shape. }\end{array}$ & Nil \\
\hline Thielman 2008 & Inpatient & $\begin{array}{l}12 \text { sessions (3 per } \\
\text { week), } 45 \text { minutes } \\
\text { per session, } 200 \\
\text { movements for each } \\
\text { session. }\end{array}$ & $\begin{array}{l}\text { For task related training, participants reached to } \\
\text { contact or grasp objects variably placed to require } \\
\text { arm movements of different amplitudes across all } \\
\text { quadrants of the table top. Common objects were } \\
\text { used that varied in size, shape and weight (eg, } \\
\text { cups, mugs, writing, eating utensils). For resisted } \\
\text { exercise, repetitive movements that required } \\
\text { proximal and distal arm muscles were carried out } \\
\text { against the resistance of the theraband. Trunk was } \\
\text { restrained in both groups. }\end{array}$ & $\begin{array}{l}\text { Task related training } \\
\text { and resisted exer- } \\
\text { cises. }\end{array}$ \\
\hline Woodbury 2009 & Outpatient/ inpatient & $\begin{array}{l}14 \text { day mCIMT } \\
\text { protocol and } 10 \\
\text { days of inclinic task } \\
\text { practice for } 6 \text { hours } \\
\text { per day }\end{array}$ & $\begin{array}{l}\text { Modified CIMT protocol along with trunk re- } \\
\text { straint training. Tasks progressed in difficulty as a } \\
\text { participant demonstrated success }\end{array}$ & mCIMT \\
\hline
\end{tabular}

Table 4. Effect sizes for the trial 1 (SM Michaelsen et al. 2001).

\begin{tabular}{|c|c|c|c|c|}
\hline \multirow{2}{*}{ Outcome measure } & \multicolumn{2}{|c|}{ Effect sizes } & \multicolumn{2}{|c|}{$\begin{array}{l}\text { Percentage change } \\
\text { From comparison to treatment }\end{array}$} \\
\hline & Trunk free & Trunk restrained & Trunk free & Trunk restrained \\
\hline Elbow extension & 1.32 very large effect & 1.24 very large effect & -27 medium decrease & -15 medium decrease \\
\hline $\begin{array}{l}\text { Shoulder horizontal } \\
\text { adduction }\end{array}$ & 1.89 huge effect & 2.19 Huge effect & -41 large decrease & -44 large decrease \\
\hline Peak velocity & 0.84 large effect & 1.40 very large effect & -22 medium decrease & -38 large decrease \\
\hline No. Of peaks & 1.26 very large effect & 1.89 huge effect & 87 huge increase & 100 huge decrease \\
\hline Index of curvature & 0.83 large effect & 0.76 large effect & 12 small increase & 11 small increase \\
\hline Slope of angle & 1.17 very large effect & 0.44 medium effect & -54 very large decrease & -17 medium decrease \\
\hline
\end{tabular}

\subsubsection{Trunk Restraint Training Combined with Task Related Training and Resisted Exercise}

G. Thielman et al. [12] in his study included 5 stroke patients in task related training group and 6 stroke patients in resisted exercise group. After the training, 3D Motion analysis system was used for testing. He con- cluded that training done by restricted truncal motion during task related training improved the precision of reaching more than during resisted exercise. The effect sizes for elbow extension (in midline) is 0.08 (Negligible effect) and for trunk flexion (in midline) is 0.8 (Large effect). The percentage change from comparison to treat- 
Normalizing the Arm Reaching Patterns after Stroke through Forced Use Therapy- A Systematic Review

Table 5. Effect sizes for the trial 2 (SM Michaelsen et al. 2004).

\begin{tabular}{|c|c|c|}
\hline Outcome measure & Effect sizes & $\begin{array}{l}\text { Percentage change } \\
\text { From comparison to treatment }\end{array}$ \\
\hline \multicolumn{3}{|c|}{ Performance outcome measures } \\
\hline Velocity peaks & 0.04 negligible effect & 2 negligible change \\
\hline Movement time & 0.02 negligible effect & 1 negligible change \\
\hline Time to peak velocity & 0.46 medium effect & 17 medium increase \\
\hline \multicolumn{3}{|c|}{ Movement variable } \\
\hline Trunk displacement & 0.58 medium effect & -33 large decrease \\
\hline Trunk rotation & 0 negligible effect & 0 negligible change \\
\hline Elbow extension & 0.29 small effect & 7 small increase \\
\hline Shoulder horizontal adduction & 0.33 small effect & 19 medium increase \\
\hline Shoulder flexion & 0.31 small effect & 19 medium increase \\
\hline
\end{tabular}

Table 6. Effect sizes for the trial 3 (SM Michaelsen et al. 2006).

\begin{tabular}{|c|c|c|c|}
\hline \multicolumn{2}{|c|}{ Outcome measure } & Effect size & Percentage change From comparison to treatment \\
\hline \multicolumn{4}{|c|}{ Clinical } \\
\hline \multicolumn{4}{|c|}{ Elbow extensor strength } \\
\hline 1. & Whole group & 0.25 small effect & 8 small increase \\
\hline 2. & Mild group & 0.23 small effect & -6 small increase \\
\hline 3. & Moderate group & 0.58 medium effect & 21 medium increase \\
\hline \multicolumn{4}{|c|}{ BBT } \\
\hline 1. & Whole group & 0.1 negligible effect & 5 small increase \\
\hline 2. & Mild group & 0.08 negligible effect & 2 negligible change \\
\hline 3. & Moderate group & 0.21 small effect & 13 small increase \\
\hline \multicolumn{4}{|c|}{ Kinematic } \\
\hline \multicolumn{4}{|c|}{ Shoulder flexion } \\
\hline 1. & Whole group & 0.17 small effect & 9 small increase \\
\hline 2. & Mild group & 0.23 small effect & 6 small increase \\
\hline 3. & Moderate group & 0.19 small effect & 13 small increase \\
\hline \multicolumn{4}{|c|}{ Peak velocity } \\
\hline 1. & Whole group & 0.07 negligible effect & 2 negligible change \\
\hline 2. & Mild group & 0.39 small effect & 10 small increase \\
\hline 3. & Moderate group & 0.22 small effect & -6 small decrease \\
\hline \multicolumn{4}{|c|}{ Smoothness, \# peaks } \\
\hline 1. & Whole group & 0.22 small effect & -10 small decrease \\
\hline 2. & Mild group & 0.15 small effect & - small decrease \\
\hline 3. & Moderate group & 0.28 small effect & -10 small decrease \\
\hline \multicolumn{4}{|c|}{ Hand trajectory straightness } \\
\hline 2. & Mild group & 0.84 large effect & 8 small increase \\
\hline 3. & Moderate group & 0.2 small effect & -3 negligible change \\
\hline
\end{tabular}


Table 7. Effect sizes for the trial 4 (Thielman et al. 2008).

\begin{tabular}{|c|c|c|c|c|c|c|}
\hline \multirow{2}{*}{ Measures } & \multicolumn{3}{|c|}{ Effect sizes } & \multicolumn{3}{|c|}{ Percentage change } \\
\hline & Ipsilateral & Midline & Contra lateral & Ipsilateral & Midline & Contra lateral \\
\hline Movement time & 0.33 small effect & $\begin{array}{c}0.12 \text { negligible } \\
\text { effect }\end{array}$ & $\begin{array}{c}0.03 \text { negligible } \\
\text { effect }\end{array}$ & 13 small increase & $\begin{array}{l}4 \text { negligible } \\
\text { change }\end{array}$ & 1 negligible change \\
\hline $\begin{array}{c}\text { First velocity } \\
\text { peak }\end{array}$ & $\begin{array}{l}0.41 \text { medium } \\
\text { effect }\end{array}$ & $\begin{array}{c}0 \text { negligible } \\
\text { effect }\end{array}$ & $\begin{array}{l}0.49 \text { medium } \\
\text { effect }\end{array}$ & 8 small increase & $\begin{array}{l}0 \text { negligible } \\
\text { change }\end{array}$ & 7 small increase \\
\hline Elbow extension & 0.27 small effect & $\begin{array}{c}0.08 \text { negligible } \\
\text { effect }\end{array}$ & 0.29 small effect & 9 small increase & $\begin{array}{l}2 \text { negligible } \\
\text { change }\end{array}$ & 11 small increase \\
\hline Trunk flexion & 0.37 small effect & 0.8 large effect & $\begin{array}{l}0.71 \text { medium } \\
\text { effect }\end{array}$ & $\begin{array}{l}-17 \text { medium } \\
\text { decrease }\end{array}$ & $\begin{array}{l}\text {-32 large } \\
\text { decrease }\end{array}$ & -42 large decrease \\
\hline Trunk rotation & $\begin{array}{l}0.74 \text { medium } \\
\text { effect }\end{array}$ & $\begin{array}{l}0.4 \text { medium } \\
\text { effect }\end{array}$ & $\begin{array}{l}0.65 \text { medium } \\
\text { effect }\end{array}$ & $\begin{array}{l}\text {-33 large de- } \\
\text { crease }\end{array}$ & $\begin{array}{l}-15 \text { medium } \\
\text { decrease }\end{array}$ & -36 large decrease \\
\hline Scapula & 1.9 huge effect & $\begin{array}{c}1.15 \text { very large } \\
\text { effect }\end{array}$ & 0.9 large effect & $\begin{array}{l}\text {-186 huge } \\
\text { decrease }\end{array}$ & $\begin{array}{l}\text {-300 huge } \\
\text { decrease }\end{array}$ & 90 huge increase \\
\hline Independent arm & 0 negligible effect & $\begin{array}{l}0.49 \text { medium } \\
\text { effect }\end{array}$ & 0.39 small effect & $\begin{array}{l}2 \text { negligible } \\
\text { change }\end{array}$ & $\begin{array}{l}16 \text { medium } \\
\text { increase }\end{array}$ & 9 small increase \\
\hline
\end{tabular}

Table 8. Effect sizes for the trial 5 (Woodbury et al. 2009).

\begin{tabular}{|c|c|c|}
\hline Outcome measure & Effect sizes & Percentage change \\
\hline \multicolumn{3}{|c|}{ Clinical evaluation } \\
\hline FMA & $\begin{array}{l}0.42 \text { medium } \\
\text { effect }\end{array}$ & 7 small increase \\
\hline WMFT & $\begin{array}{l}0.43 \text { medium } \\
\text { effect }\end{array}$ & $\begin{array}{l}-16 \text { medium } \\
\text { decrease }\end{array}$ \\
\hline MAL - AOU & 0.91 large effect & $\begin{array}{l}-28 \text { medium } \\
\text { decrease }\end{array}$ \\
\hline MAL - QOM & $\begin{array}{c}0.56 \text { medium } \\
\text { effect }\end{array}$ & $\begin{array}{l}-19 \text { medium } \\
\text { decrease }\end{array}$ \\
\hline \multicolumn{3}{|c|}{ Kinematic results } \\
\hline Peaks & 2.4 huge effect & -34 large decrease \\
\hline Index of curvature & 3.33 huge effect & -32 large decrease \\
\hline Trunk displacement & 5.53 huge effect & -36 large decrease \\
\hline $\begin{array}{l}\text { Shoulder flexion / } \\
\text { extension excursion }\end{array}$ & 0.21 small effect & 7 small increase \\
\hline $\begin{array}{c}\text { Elbow flexion / } \\
\text { extension excursion }\end{array}$ & 0 negligible effect & 11 small increase \\
\hline
\end{tabular}

ment group for elbow extension is 2 (Negligible change) and trunk flexion is -32 (Large decrease). The elbow extension increased significantly from pre-test to post test in trunk restraint group (55 degrees to 64 degrees).

\subsubsection{Trunk Restraint Training Combined with Intensive Task Practice}

ML. Woodbury et al. [13] did a pilot study in which he included 11 chronic stroke patients and 5 healthy individuals. Data were collected with 10 - camera motion analysis system. He concluded that intensive task practice structured to prevent compensatory movements and promote shoulder flexion - elbow extension coordination may reinforce development of normal reaching kinemat- ics. The effect sizes for trunk displacement are 5.53 (Huge effect). The percentage changes from comparison to treatment group trunk displacement are -36 (Large decrease). In mCIMT + Trunk restraint group, the trunk displacement is $0.13(0.01)$ in pre-test \& $0.04(0.01)$ in post-test; the elbow flexion/extension excursion is -7.48 (6.69) in pre-test \& 1.87 (1.93) in posttest.

\section{Discussion}

A considerable research effort has assessed the effects of trunk restraint training on the recovery of reaching movements in hemiparetic patients. This review identified 5 relevant trials in which one trial is a pilot study. Among 5 trials, three trials recorded the movement kinematics (outcome measure) by Optotrak Motion analysis System, in the other two trials the movement kinematics(outcome measure) were analysed by a 6 camera, 3D Motion analysis system and 10 - camera Motion Analysis System respectively. The effect sizes for the outcome measure (Kinematic analysis) were analysed which shows medium effect to very large effect favouring the trunk restraint group. There is variability in the result of the studies included in this review, since the studies included mildly to moderately affected patients there is lack of improvement resulted from the training not being challenging enough.

Reaching ability is an important component for independent living. However, survivors of stroke often rely on compensatory movement strategies to accomplish reaching tasks. Carr and shepherd [15] suggest that compensatory strategies are the result of using available movements given the poststroke state of the central system, which leads to long-term functional limitations. Hence Michaelsen et al. studied the effectiveness of 
trunk restraint training on arm recovery in stroke patients and demonstrated that trunk restraint is a treatment paradigm which decreases the compensatory strategies.

Since task related training $[19,20]$ and resisted exercise $^{21}$ demonstrated enhanced recovery in stroke patients, Thielman et al. [12] compared the effects of task related training and resisted exercise combined with trunk restraint training in his recent trial. His results added one more stone in the crown of trunk restraint training. Extensive practice using task related training with truncal restraint appears to be a more effective approach to rehabilitate reaching with the hemiparetic arm.

\subsection{How Trunk Restraint Training Improves Arm Reaching?}

The effects of trunk restraint indicate that hemiparetic patients did not use their potential joint range for free arm movements. A likely explanation stems from the findings of Levin et al. [16]. They defined articular ranges in which hemiparetic patients could make isolated elbow flexion and extension movements by using a reciprocal muscle activation pattern. The increase in joint ranges with trunk restraint may be partly due to an adaption involving anticipation of changed external load conditions.

Another possibility is that the adaptation was triggered by somatosensory input from the trunk or shoulder caused by the trunk restraint [17]. In other words, patients are forced to make movements "out of synergy", which probably involves a focussed and greater effort on their part. This is similar to the strategy of constraining the unaffected arm [18] to force the patient to make more use of the affected arm with the additional feature that reduction of compensatory movement patterns is also targeted. This was proved by the recent findings of ML. Woodbury et al. [13]. Physical trunk restraint can be considered similar to "Manual guidance" in which spatial constraints are used to promote use of more optimal movement patterns [10].

In this training paradigm, external feedback, that is, explicit information was inherently built into the task practice with trunk restraint context both as knowledge of results (KR) and knowledge of performance (KP). For example, the participant received KR by either achieving or failing to achieve the task- goal. Additionally, the participants received KP via an afferent cue from the trunk restraint if he/she leaned forward [13].

\subsection{Trunk Restraint Training in Future}

Findings of Hsu WL et al. [22] suggest that the muscles in the affected ankle cannot be recruited timely and efficiently for the reaching task in stroke patients, as with relative recovery in lower limbs. In other words, they do not generate normal motor recruitment patterns to ac- complish the motor task. It has been reported that even when the recovery is scored high in test situations, stroke patients do not spontaneously use their paretic side in daily living situations [23]. Future studies should emphasize some interventions to the hemiplegic lower limb while giving trunk restraint training to the hemiplegic upper limb.

The interaction between arm and trunk movements may also be altered in patients with hemiparesis due to the excessive displacement of the trunk for arm transport as has been previously reported during unimanual reaching and grasping [9-26]. The increased role of the trunk for arm transport and problems of trunk control in individuals with hemiparesis may represent additional challenges to inter-segment coordination and result in a destabilization of posture during tasks requiring arm movements from a standing position [27]. In daily living, reaching is more likely to be performed in a standing position $[28,29]$. In future, we recommend to study the influence of trunk restraint training in arm reaching in standing position.

It has long been recognized by clinicians $[7,30]$ that once compensation has been learned, it is very difficult to modify. Indeed, prolonged use of compensatory trunk movements to reach targets placed within arm's length may result in the system learning not to use arm joints for reaching and grasping (learned nonuse) [18]. So that recovery of independent use of these joints would be discouraged. Compensatory movement strategies may be very difficult to unlearn [31], frustrating efforts to improve movement for both patient and therapist. Though all the trials included in this review demonstrated positive results for trunk restraint training on arm reaching movements, for maintaining the training effects for the rest of the day we suggest to study the effects of additional usage of strapping or splints or brace with trunk restraint training.

It is already known that stroke patients are deconditioned; hence training programs should combine physical conditioning and motor learning principles which will give the best and most permanent effect on motor recovery [32]. Trunk restraint training didn't address whether the intervention improved functional capacity of the arm, because it was expected that longer term practice would be necessary to affect change in this dimension. Hence in future, studies on trunk restraint training can also include physical conditioning program along with long term practice.

Young and Schmidt showed that less retention of learning occurs when continuous feedback is given compared with less frequent feedback. Hence further studies are necessary to determine the efficacy of faded trunk restraint program [34]. 


\section{Limitations}

The limitations of this review are,

1) Among the studies included in this review, only one study is randomized controlled trial which is suitable to find out the clinical efficacy.

2) The study quality of included papers is not evaluated, because we included descriptive studies in the absence of randomized controlled trials.

3) The kinematic analysis done in the studies included in this review used different movement variables; hence it is difficult to summarize the results.

\section{Conclusions}

This review identified 5 full text trials of trunk restraint training in stroke patients. The results of our review demonstrated that the use of trunk restraint as a treatment paradigm aimed at decreasing compensatory strategies has the potential of becoming an effective therapy. It shows that under lying "normal” patterns of movement coordination are not entirely lost after stroke and that appropriate treatments may be applied to uncover them to maximize function. One cost of this recovery may be a short-term decrease in movement speed. Our review also suggests that trunk restraint training + other rehabilitation program encouraged near to normal coordination patterns which were not seen in the absence of trunk restraint training in the rehabilitation protocol. Further researches with randomized control trials are necessary to determine the long term effect and the clinical efficacy of the trunk restraint training.

\section{REFERENCES}

[1] S. J. Page, S. Sisto, P. Levine and R. E. Mcgrath, "Efficacy of Modified Constraint-Induced Movement Therapy in Chronic Stroke: A Single-Blinded Rendomized Controlled Trial," Archives of Physical Medicine and Rehabilitation, Vol. 85, No. 1, 2004, pp. 14-18.

[2] N. A. Bernstein, "The Coordination and Regulation of Movement,” Pergamon Press, Oxford, UK, 1967.

[3] M. C. Cirstea and M. F. Levin, "Compensatory Strategies for Reaching in Stroke,” Brain, Vol. 123, No. 5, 2000, pp. 940-953.

[4] I. Q. Whishaw, "Loss of the Innate Cortical Engram for Action Patterns Used in Skilled Reaching and the Development of Behavioural Compensation Following Motor Cortex Lesions in the Rat,” Neuropharmacology, Vol. 39, No. 5, pp. 788-805.

[5] K. M. Friel and R. J. Nudo, "Recovery of Motor Function after Cortical Injury in Primates: Compensatory Movement Patterns Used During Rehabilitative Training," Somatosensory and Motor Research, Vol. 15, No. 3, 1998, pp. 173-189.

[6] M. C. Cirstea, A. Ptito and M. F. Levin, “Arm Reaching
Improvements with Short Term Practice Depend on the Severity of the Motor Deficit in Stroke," Experimental Brain Research, Vol. 152, No. 4, 2003, pp. 476-488.

[7] L. Ada, C. Canning, J. H. Carr, S. L. Kilbreath and R. B. Shepherd, "Task-Specific Training of Reaching and Manipulation,” In: K. M. B. Bennet, U. Castiello, Eds., Insights into Reach and Grasp Movement, Elsevier-Biosoft, Cambridge, UK, 1994, pp. 239-265.

[8] J. W. Krakauer, "Motor learning: Its Relevance to Stroke Recovery and Neurorehabilitation," Current Opinion in Neurology, Vol. 19, No. 1, 2006, pp. 84-90.

[9] S. M. Michelsen, A. Lutta, A. Roby-Brami and M. F. Levin, "Effect of Trunk Restraint on the Recovery of Reaching Movements in Hemiparetic Patients,” Stroke, Vol. 32, No. 8, 2001, pp. 1875-1883.

[10] S. M. Michaelsen, D. E. A. and M. F. Levin, "Short Term Effects of Practice with Trunk Restraint on Reaching Movements in Patients with Chronic Stroke,” Stroke, Vol. 35, No. 8, 2004, pp. 1914-1919.

[11] S. M. Michaelsen, R. Dannenbawn and M. F. Levin, "Task-Specific Training with Trunk Restraint on Arm Recovery in Stroke,” Stroke, Vol. 37, No. 1, 2006, pp. 186-192.

[12] G. Thielman, T. Kaminski and A. M. Gentile, "Rehabilitation of Reaching after Stroke: Comparing 2 Training Protocol Utilizing Trunk Restraints,” Neurorehabil Neural Repair, Vol. 22, No. 6, 2008, pp. 697-705.

[13] M. L. Woodbury, D. R. Howland, T. E. Mcguirk, S. B. Davis, C. R. Senesac, S. Kautz and L. G. Richards, "Effects of Trunk Restraint Combined with Intensive Task Practice on Poststroke Upper Extremity Reach and Function: A Pilot Study,” Neurorehabil Neural repair, Vol. 23, No. 1, 2009, pp. 78-91.

[14] J. Cohen, "Statistical Power Analysis for the Behavioural Sciences,” 2nd Edition, Academic Press, New York, 1977.

[15] J. Carr and R. Shepherd, "Movement Science: Foundations for Physical Therapy in Rehabilitation,” 2nd Edition, Aspen Publishers, Gaithersburg, 2000.

[16] M. F. Levin, R. W. Selles, M. H. G. Verheul and O. G. Meijer, "Deficits in the Range of Regulation of Central Control over Arm Movement in Stroke Patients," Brain Research, Vol. 853, 2000, pp. 352-369.

[17] S. V. Adamovich, P. Archambault, M. Ghafouri, M. F. Levin, H. Poizner and A. G. Feldman, "Hand Trajectory Variance in Reaching Movements Involving the Trunk," Experimental Brain Research, Vol. 138, No. 3, 2001, pp. 288-303.

[18] E, Taub, N. E. Miller, T. A. Novack, E. W. Cook III, W. C. Fleming, C. S. Neomuceno, J. S. Connell and J. E. Crago, "Technique to Improve Chronic Motor Deficit after Stroke,” Archives Physical Medicine Rehabilitation, Vol. 74, No. 4, pp. 347-354.

[19] C. M. Dean, C. L. Richards and F. Malouin, “Task-Related Circuit Training Improves Performance of Locomotor Tasks in Chronic Stroke: A Randomized Controlled Pilot Trial,” Archives Physical Medicine Rehabilitation, Vol. 81, No. 4, pp. 409-417. 
[20] C. M. Dean and R. B. shepherd, “Task Related Training Improves Performance of Seated Reaching Tasks after Stroke,” Stroke, Vol. 28, No. 4, 1997, pp. 722-728.

[21] S. L. Morris, K. J. Dodd and M. E. Morris, "Outcomes of Progressive Resistance Strength Following Stroke: A Systematic Review," Clinical Rehabilitation, Vol. 18, No. 1, 2004, pp. 27-39.

[22] W. L. Hsu, Y. R Yang, C. T. Hong and R. V. Wang, “Ankle Muscle Activation during Functional Reach in Hemiparetic and Healthy Subjects," American Journal of Physical Medicine and Rehabilitation, Vol. 84, No. 10, 2005, pp. 749-755.

[23] K, Andrews and J, Stewart, "Stroke Recovery: He Can But Does He?” Rheumatology Rehabilitation, Vol. 18, No. 1, 1979, pp. 43-48.

[24] C. M. Cirstea and M. F. Levin, "Compensatory Strategies for Reaching in Stroke,” Brain, Vol. 123, No. 5, 2000, pp. 940-953.

[25] M. F. Levin, S. M. Michaelsen, C. M. Cirstea and A. B. Roby, "Use of the Trunk for Reaching Targets Placed within and Beyond the Reach in Adult Hemiparesis," Experimental Brain Research, Vol. 143, No. 2, pp. 171180.

[26] A. B. Roby, A. Feydy, M. Combeaud, E. V. Biryukova, B. Bussel and M. F. Levin, "Motor Compensation and Recovery for Reaching in Stroke Patients," Acta Neurologica Scandinavica, Vol. 107, No. 5, 2003, pp. 369-381.

[27] K. L. Ustinova, V. M. Goussev, R, Balasubramaniam and
M. F. Levin, "Disruption of Coordination between Arm, Trunk and Centre of Pressure Displacement in Patients with Hemiparesis,” Motor control, Vol. 8, No. 2, 2004, pp. 139-159.

[28] J. Carr and R. Shepherd, "Stroke Rehabilitation: Guidelines for Exercise and Training to Optimize Motor Skill," Elsevier, New York, 2003.

[29] P. Vanvliet, M. Sheriddan, D. G. Kerwin, et al., "The Influence of Functional Goals on the Kinematics of Reaching Following Stroke,” Neurology Report, Vol. 19, No. 1, 1995, pp. 11-16.

[30] N. A. Bernstein, "The Coordination and Regulation of Movement,” Pergamon Press, Oxford, UK, 1967.

[31] N. A. Bernstein and G. R. Buravtseva, "Coordination Disturbances and Restitution of the Biodynamics of Gait after Brain Damage," Thesis, $7^{\text {th }}$ session, Academy of Medical Science, Institute of neurology, Moscow, 1954.

[32] J. Whitall, "Stroke Rehabilitation Research: Time to Answer More Specific Questions?” Neurorehabil Neural Repair, Vol. 18, No. 1, 2004, pp. 3-8.

[33] W. Thalheimer and S. Cook, "How to Calculate Effect Sizes from Published Research: A Simplified Methodology,” A Work-Learning Research Publication, November 2009. http://work-learning.com/effect_sizes.htm

[34] D. E. Young and R. A. Schmidt, "Augmented Kinematic Feedback for Motor Learning,” Journal of Motor Behavior, Vol. 24, No. 3, 1992, pp. 261- 273. 